Pesq. Vet. Bras. 36(7):642-646, julho 2016

DOI:10.1590/S0100-736X2016000700014

\title{
Avaliação dos fatores etários sobre a função renal de ovelhas Santa Inês ${ }^{1}$
}

\author{
Laura C.S. Henriques², Lilian Gregory ${ }^{2 *}$, Huber Rizzo ${ }^{3}$, Marjorie Y. Hasegawa² \\ e Enoch B.S. Meira Jr²
}

\begin{abstract}
Henriques L.C.S., Gregory L., Rizzo H., Hasegawa M.Y. \& Meira Jr E.B.S. 2016. [Evaluation of the renal function in aging Santa Ines ewes.] Avaliação dos fatores etários sobre a função renal de ovelhas Santa Inês. Pesquisa Veterinária Brasileira 36(7):642646. Departamento de Clínica Médica, Faculdade de Medicina Veterinária e Zootecnia, Universidade de São Paulo, Av. Prof. Dr. Orlando Marques de Paiva 87, Cidade Universitária, São Paulo, SP 05508-270, Brazil. E-mail: lgregory@usp.br

This study evaluated kidney function of healthy Santa Inês ewes, bred in São Paulo State. The aim of this paper was to establish standard reference values and stipulate value variation caused by age group factor. We determined seric and urinary levels of urea, creatinine, sodium and potassium, and urinary GGT from 128 ewes, divided into 4 groups according to age. Also urinalysis was made in 128 urine samples. No significant statistical difference was found regarding density values between all groups, although there was an increase in urea values, creatinine and sodium, and an decrease in urinary proteins and GGT in group 2,3 and 4 older than group 1 . In relation to the seric parameters, there was significative statistical difference in urea and creatinine values between the groups, as an increase in urea and creatinine. Potassium decreased in the older groups 2, 3 and 4. Evaluating the results obtained for renal function, we found that the mean values of density were $1.03 \pm 0.01, \mathrm{pH}$ $7.1 \pm 1.35$, urea (mg/dL) $1342 \pm 1085$, creatinin $42.39 \pm 23,36$, total protein (g/dL) $5.61 \pm 2.88$, GGT (U/L) 1.44 \pm 1.31 , sodium and potassium $(\mathrm{mmol} / \mathrm{L})$ were $15.93 \pm 20.13$ and $240 \pm 117$ respectively. In the serum medium values were: urea $(\mathrm{mg} / \mathrm{dL}) 32.33 \pm 19.81$, creatinine $1.22 \pm 0.20$, sodium and potassium $(\mathrm{mmol} / \mathrm{L}) 145.7 \pm 8.8$ and $5.5 \pm 1.30$ respectively.
\end{abstract}

INDEX TERMS: Sheep, kidney function, urea, creatinin.

RESUMO.- Este estudo avaliou a função renal de fêmeas ovinas hígidas da raça Santa Inês, criadas no Estado de São Paulo, com o objetivo de estabelecer valores de referência, além de determinar possíveis variações dos valores de seus parâmetros causados por fatores etários. Foram determinados os valores de ureia, creatinina, sódio e potássio séricos e urinários, e os valores de GGT urinário de 128 animais, divididos em 4 grupos de acordo com a idade. Foi realizada, também a urinálise das 128 amostras de urina. Não foi observada diferença significativa dos valores de densidade

\footnotetext{
${ }^{1}$ Recebido em 25 de maio de 2015.

Aceito para publicação em 21 de fevereiro de 2016

${ }^{2}$ Departamento de Clínica Médica, Faculdade de Medicina Veterinária e Zootecnia, Universidade de São Paulo (USP), Av. Prof. Dr. Orlando Marques de Paiva 87, Cidade Universitária, São Paulo, SP 05508-270, Brasil. *Autor para correspondência: lgregory@usp.br

${ }^{3}$ Departamento de Medicina Veterinária, Universidade Federal Rural de Pernambuco, Dois Irmãos, Recife, PE 52171-900, Brasil.
}

entre todos os grupos. Entretanto, constatou-se aumento de valores de ureia, creatinina, sódio e diminuição de proteínas e GGT urinários nos grupos 2, 3 e 4 que eram mais velhos do que o grupo 1. Em relação aos parâmetros séricos, observou-se diferença significativa dos valores de ureia e creatinina entre os grupos, pois uréia e creatinina aumentaram e potássio diminuiu nos animais do grupo 2, 3 e 4 que eram mais velhos. Avaliando-se os resultados obtidos para os exames da função renal, verificou-se que os valores médios na urina da densidade foi de $1,03 \pm 0,01 ; \mathrm{pH} 7,71 \pm 1,35$; ureia em $\mathrm{mg} / \mathrm{dL}$ foi $1342 \pm 1085$; de creatinina $42,39 \pm 23,36$; de proteínas totais em g/dL foi de 5,61 $\pm 2,88$; GGT em U/L foi de $1,44 \pm 1,31$; sódio e potássio em $\mathrm{mmol} / \mathrm{L}$ foi de $15,93 \pm 20,13$ e $240 \pm 117$ respectivamente. No soro verificou-se que os valores médios foram: de ureia em $\mathrm{mg} / \mathrm{dL} 32,33 \pm 19,81$; de creatinina $1,22 \pm 0,20$; de sódio e potássio em $\mathrm{mmol} / \mathrm{L}$ foram de $145,7 \pm 8,8$ e $5,5 \pm 1,30$ respectivamente.

TERMOS DE INDEXAÇÃO: Ovinos, função renal, ureia, creatinina. 


\section{INTRODUÇÃO}

O estudo para determinação ou avaliação da variabilidade dos valores de referência de parâmetros fisiológicos de animais domésticos sadios é de grande importância para que o clínico veterinário possa analisar e comparar possíveis alterações decorrentes de diversas doenças. Como existem limitações do exame físico em detectar alterações da função de certos órgãos ou sistemas, as provas bioquímicas, que avaliam essas funções, realizadas no soro sanguíneo dos animais domésticos, representam um excelente subsídio ao diagnóstico clínico de inúmeras enfermidades (Meira Jr et al. 2009), destacando-se aquelas com sede ou repercussões sobre os rins e que, frequentemente, alteram as funções ou estruturas destes órgãos.

Por estas razões, usualmente na rotina clínica os referidos exames são reunidos em grupos, como de provas avaliadoras da função renal, considerando as seguintes determinações bioquímicas no soro sanguíneo e na urina: teores de ureia e creatinina séricas e urinárias, íons como sódio e potássio sérico, urinálise, determinação de GGT urinária e íons sódio urinário. Essas provas têm sido classicamente recomendadas para a avaliação da função renal, fornecendo subsídios, para o diagnóstico ou prognóstico de inúmeras nefropatias (Araújo et al. 2009). Os fatores de variabilidade descritos como possíveis causadores de significativas alterações nos resultados das provas bioquímicas realizadas em amostras de soro sanguíneo de animais sadios podem ser divididos em intrínsecos e extrínsecos. Os intrínsecos pertinentes às condições inerentes do individuo (espécie, raça, idade, sexo) e os extrínsecos relacionados à adaptação dos animais ao meio ambiente em que vivem, ou ainda ao sistema de criação em que são mantidos. Deve-se ainda considerar a variação causada pelo método utilizado para as determinações, pela técnica de colheita ou de conservação de amostras.

A deficiência dos mecanismos normais de micção tais como atonia vesical por comprometimento da inervação, obstrução anatômica ou funcional causados por urolitíase, neoplasia, sondagem e trauma, além de anormalidades anatômicas como ureter ectópico e malformações uretrais e alguns procedimentos cirúrgicos como uretrostomia e cistotomia estão envolvidos e podem favorecer o desenvolvimento de uma infecção do trato urinário (Osborne \& Lees 1995). A doença renal adquirida geralmente progride para o estágio de insuficiência e falência renal. A causa inicial da doença pode ainda persistir e contribuir para a contínua perda de néfrons como acontece na pielonefrite, glomerulonefrite imunomediada, hipercalcemia ou nefropatia tóxica com persistente exposição à toxina (Polzin et al. 2001, Schrier et al. 2004). Os processos associados à doença renal congênita ou familiar estão geralmente relacionados à displasia renal, hipoplasia renal, glomerulopatia e alterações tubulares (Coelho et al. 2001).

Considerando-se a geração de substâncias no sistema orgânico, a maior porção da ureia é sintetizada no fígado, a partir da amônia proveniente do catabolismo proteico e da absorção intestinal (Duncan \& Prasse 1977, Coles 1986, Kaneko 2008) e uma menor fração é originaria da alimentação (Duncan \& Prasse 1977, Kaneko 2008).

A creatinina sérica é uma substância nitrogenada não proteica, formada a partir do metabolismo muscular da creatina e da fosfocreatina, sendo maior em animais com maior massa muscular. Se compararmos, filhotes ou adultos jovens possuem uma taxa maior de creatinina do que animais mais velhos que vão perdendo massa muscular por isso seus valores sofrem influência dos fatores etários e sexuais. A ureia e a creatinina são eliminadas do organismo através dos rins, que são responsáveis pela depuração das duas referidas substâncias nitrogenadas não proteicas. A ureia é excretada junto com outros produtos do catabolismo proteico e o acúmulo destes, junto com a creatinina é conhecido como azotemia. A creatinina é filtrada livremente ao nível glomerular, não sendo reabsorvida nos túbulos renais, por tal razão é considerada um indicador mais especifico de lesão renal (Coles 1986).

O sódio representa o mais significativo cátion extracelular, enquanto o potássio e o magnésio são os principais cátions intracelulares. 0 equilíbrio dos íons sódio e potássio são mantidos mediante um sistema enzimático que consome energia (bomba de Na-K-ATP) que não só retira o sódio do interior das células, mas também ajuda a introduzir o potássio nas mesmas. Uma das formas mais comuns de desequilíbrio dos fluidos corpóreos é aquela causada pela desidratação, decorrente usualmente, da excessiva perda de água e eletrólitos ocasionada por determinadas doenças. $\mathrm{Na}$ avaliação precoce da instalação da alteração/lesão renal, alguns autores (Greco et al. 1985, Diéz \& Biollaz 1979, Garry et al. 1990a, 1990b, Pinheiro et al. 1990, Schrier et al. 2004) indicaram as provas de concentração, avaliação de excreção de eletrólitos e de enzimas urinárias, sedimentoscopia, teste de depuração da creatinina endógena ou exógena e determinação da presença de proteinúria e glicosúria renal. Já a avaliação quantitativa de ureia e de creatinina não é indicada como prova precoce de alteração da função glomerular, pois os seus níveis sanguíneos só se alteram quando 3/4 do parênquima renal se encontra comprometido.

Poucas pesquisas sobre a função renal em ovinos foram encontradas na literatura veterinária nacional ou internacional confirmando o fato da necessidade de estudos sobre o assunto. 0 estudo da função renal é relevante principalmente nesta espécie devido a alta incidência de enfermidades no sistema urinário, como por exemplo a urolitíase, intoxicação por cobre, cistite etc., confirmada pela literatura (Riet-Correa et al. 2008, Ortolani et al. 2011, Antonelli et al. 2012).

\section{MATERIAL E MÉTODOS}

Para este estudo foram colhidas amostras de sangue e de urina de 128 fêmeas segundo John (2003). Os animais eram hígidos, da raça Santa Inês, criados no Estado de São Paulo. 0 exame físico realizado seguiu os métodos semiológicos preconizados por Rosenberger (1993) e foi aprovado o experimento na comissão de bioética da Faculdade de Medicina Veterinária da Universidade de São Paulo.

As amostras foram subdivididas em quatro grupos etários segundo a classificação de Reichmann (1972) que utilizou 80 animais e 20 em cada grupo e propõe a divisão em 4 grupos: grupo 1 com animais de 0 a seis meses de idade; grupo 2, animais com 7 a 18 meses; grupo 3, 19 a 48 meses e no grupo 4, idade superior a 48 meses.

As amostras de urina foram obtidas por micção espontânea ou, em poucos casos, por meio de cateterismo vesical quando o animal não urinava depois do estímulo, utilizando-se sonda de metal, as 
amostras foram mantidas sob refrigeração até a análise. Os exames físico e químico da urina foram realizados segundo técnica descrita por Hagiwara \& Mamizuka(1998), com o auxílio de tiras reagentes da marca Combur-Test ${ }^{\circledR}$ (Roche, Basiléia, Suíça), para determinação do pH e um refratômetro para a determinação da densidade. As amostras de urina foram centrifugadas a 1000 RPM durante 5 minutos, sendo o sobrenadante destinado às provas físicas e químicas e avaliação do sedimento, ao exame microscópico, conforme descrito por Coles (1986). 0 exame físico e o sedimento foram realizados em um intervalo de 24 horas após a colheita e para a realização dos exames bioquímicos, as amostras foram armazenadas em "freezer" a $-20^{\circ} \mathrm{C}$. As concentrações urinárias de ureia foram quantificadas, em mg/dL, com, segundo metodologia descrita por (Talke \& Schubert 1975). A creatinina urinária foi realizada segundo método de Jaffe modificado, conforme técnica descrita por Lustgarten \& Wenk (1972). A proteína urinária foi quantificada com a utilização do kit vermelho de pirogalol da BioSystems ${ }^{\circledR}$, Foster City, Califórnia, USA e para a fração GGT foi utilizado o kit IFCC da BioSystems ${ }^{\circledR}$, Foster City, Califórnia, USA. As frações de excreção de sódio e de potássio urinário foram determinadas de acordo com a metodologia descrita em (Brenner 1991).

As amostras de sangue foram colhidas por punção da veia jugular externa, utilizando-se agulhas $30 \times 0,7 \mathrm{~mm}$ com duas pontas, em tubos siliconados, sem anticoagulante, providos de tampa de borracha e com vácuo suficiente para aspirar $10 \mathrm{~mL}$ de sangue (Sistema Vacutainer ${ }^{\circledR}$, New Jersey, NY, USA). As amostras foram mantidas sob refrigeração e levadas para o laboratório de pesquisa do Departamento de Clínica Médica da Faculdade de Medicina Veterinária e Zootecnia da Universidade de São Paulo, onde foram centrifugadas a $1000 \mathrm{~g}$ por 15 minutos para a obtenção do soro, em seguida as amostras obtidas foram armazenadas em tubos plásticos no "freezer" a $-20^{\circ} \mathrm{C}$ até que fossem realizadas as análises necessárias. Foram dosados os valores de ureia, creatinina, sódio e potássio sérico. A ureia foi quantificada, em $\mathrm{mg} / \mathrm{dL}$, com uso de analisador bioquímico automático da marca $\mathrm{AMS}^{\circledR}$, modelo Liasys ${ }^{\circledR}$, Roma, Itália, segundo metodologia descrita por Talke \& Schubert (1975), utilizando-se kit comercia da marca Diasys ${ }^{\circledR}$, Holzheim, Alemanha. A creatinina sérica foi realizada segundo método de Jaffe modificado, conforme técnica descrita por Lustgarten \& Wenk (1972). Os teores séricos de sódio e potássio foram analisados e em analisador bioquímico automático e os teores urinários através da fotometria de chama em Fotômetro de Chama modelo FC-130, da marca CELM (Korzun \& Miller 1987).

Para verificar se os dados possuíam distribuição normal foi utilizado o Teste de Normalidade de Anderson-Darling. Na detecção de diferenças dos valores pesquisados entre os grupos foi utilizado o teste não paramétrico de Kruskal-Wallis com Intervalo de Confiança igual a 95\%. Foi utilizado o teste de Mann-Whitney monocaudal com Intervalo de Confiança igual a 97,5\% quando da necessidade de se estabelecer uma relação de grandeza entre um grupo e todos os outros. E a fim de se investigar diferenças entre apenas dois grupos, foi utilizado o teste de Mann-Whitney bicaudal com Intervalo de Confiança de 95\%.

\section{RESULTADOS}

A análise da coloração das amostras de urina das 128 ovinos fêmeas, revelou que a coloração esperada para a urina dos animais desta raça varia predominantemente entre o amarelo citrino e amarelo palha. Em relação ao aspecto da urina esta se apresentou límpida em $88 \%$ das amostras e com odor sui generis em $97 \%$ dos casos. Na avaliação de sedimentos notou-se que apesar da presença de cristais serem raras os mais prevalentes foram o trifosfato.
No Quadro 1 estão os resultados das médias e desvios-padrão obtidos da avaliação de densidade, proteína, $\mathrm{pH}$, ureia, creatinina, GGT, sódio e potássio da urina das 128 fêmeas (geral) ovinas da Raça Santa Inês, dispostos de acordo com os valores encontrados para os grupos etários e geral.

Não foi encontrada diferença significativa dos valores de densidade entre todos os grupos $(P=0,352)$. A média encontrada para todos os animais foi de 1,034, com desvio-padrão de 0,01.

Observou-se diferença significativa dos valores de proteína entre os grupos $(P=0,004)$. Os valores de proteína encontrados foram maiores no grupo 4 do que nos demais $(P=0,0063)$. Os valores de proteína encontrados no grupo 1 são maiores do que os encontrados nos grupos 2 e $3(P=$ 0,0047). Não foi encontrada diferença significativa entre os valores de proteína dos grupos 1 e $4(P=0,3977)$. A média encontrada foi 5,61 e o desvio-padrão foi de 2,88.

Em relação ao pH, não foi encontrada diferença significativa de seus valores entre os grupos $(P=0,064)$. A média encontrada foi 7,71 com desvio-padrão de 1,35. Houve diferença significativa entre os valores de ureia urinária entre os grupos $(P=0,000)$. Os dados de ureia urinária encontrados no grupo 1 são menores do que os encontrados nos demais grupos $(P=0,0000)$. A média observada foi de 1342 com desvio-padrão de 1085.

Houve significativa entre os valores de creatinina urinária entre os grupos $(P=0,017)$. Os valores de creatinina urinária encontrados para o grupo 1 foram menores do que os encontrados para os outros grupos $(P=0,0028)$.

Encontrou-se diferença significativa entre os valores de GGT urinário entre os grupos $(P=0,018)$. Os valores de GGT encontrados no grupo 1 foram maiores do que os encontrados nos demais grupos $(P=0,0013)$. A média encontrada foi 1,44 com desvio-padrão de 1,31.

Foi encontrada diferença significativa entre os valores de sódio urinário entre os grupos $(P=0,011)$. Os valores de sódio urinário encontrados no grupo 1 foram maiores do que os encontrados nos demais grupos $(P=0,0021)$.

Em relação ao sódio urinário a média encontrada foi de 15,93 com desvio-padrão de 20,13.

Não foi encontrada diferença significativa dos valores de potássio urinário entre todos os grupos $(P=0,009)$. A média encontrada para todos os animais foi de 1,03 , com desvio-padrão de 0,01.

No Quadro 2 estão os resultados das médias e desvios-padrão obtidos da avaliação das concentrações sérica de ureia, creatinina, sódio e potássio das 128 fêmeas ovinas da Raça Santa Inês, dispostos de acordo com os valores encontrados para os grupos etários e geral.

Foi encontrada diferença significativa entre os valores de ureia sérica entre os grupos $(P=0,000)$. Os valores de ureia sérica encontrados no grupo 1 são menores do que os encontrados nos demais grupos $(P=0,000)$. A média encontrada foi 32,33 com desvio-padrão de 19,81.

Observou-se diferença nos valores de creatinina sérica entre os grupos $(P=0,000)$. Os valores de creatinina sérica no grupo 1 são menores do que os encontrados nos demais grupos $(P=0,000)$ e os valores do grupo 4 são menores do que os encontrados nos demais grupos $(P=0,0042)$. Não foi encontrada diferença significativa entre os grupos 1 e $4(P=0,170)$. A média observada foi de 1,22 com desvio-padrão de 0,20. 
Quadro 1. Valores da média e do desvio padrão de densidade, proteína, pH, uréia, creatinina, GGT, sódio e potássio da urina de fêmeas ovinas sadias, da raça Santa Inês, criadas no Estado de São Paulo, dividido por grupos etários e geral

\begin{tabular}{lccccc}
\hline Variável & Grupo 1 & Grupo 2 & Grupo 3 & Grupo 4 & Geral \\
\cline { 2 - 6 } & \multicolumn{5}{c}{ Média (desvio padrão) } \\
\hline Densidade & $1,036^{\mathrm{a}}(0,01)$ & $1,035^{\mathrm{a}}(0,01)$ & $1,031^{\mathrm{a}}(0,01)$ & $1,036^{\mathrm{a}}(0,01)$ & $1,034(0,01)$ \\
Proteína(g/dL) & $6,16^{\mathrm{a}}(2,77)$ & $4,91^{\mathrm{b}}(2,77)$ & $4,43^{\mathrm{b}}(2,63)$ & $6,82^{\mathrm{a}}(2,84)$ & $5,61(2,88)$ \\
$\mathrm{pH}$ & $7,79^{\mathrm{a}}(1,14)$ & $7,97^{\mathrm{a}}(0,96)$ & $6,97^{\mathrm{a}}(1,79)$ & $8,1^{\mathrm{a}}(1,11)$ & $7,71(1,35)$ \\
Uréia(mg/dL) & $621^{\mathrm{a}}(396)$ & $1441^{\mathrm{b}}(1097)$ & $1595^{\mathrm{b}}(1222)$ & $1903^{\mathrm{b}}(1083)$ & $1342(1085)$ \\
Creatinina(mg/dL) & $33,58^{\mathrm{a}}(20,34)$ & $52,61^{\mathrm{b}}(30,65)$ & $41,57^{\mathrm{b}}(17,28)$ & $44,14^{\mathrm{b}}(20,25)$ & $42,39(23,36)$ \\
GGT(U/L) & $1,90^{\mathrm{a}}(1,22)$ & $1,03^{\mathrm{b}}(1,08)$ & $1,26^{\mathrm{b}}(1,11)$ & $1,47^{\mathrm{b}}(1,67)$ & $1,44(1,31)$ \\
Sódio(mmol/L) & $31,75^{\mathrm{a}}(29,04)$ & $6,41^{\mathrm{b}}(3,99)$ & $17,87^{\mathrm{b}}(19,35)$ & $11,09^{\mathrm{b}}(12,43)$ & $15,93(20,13)$ \\
Potássio(mmol/L) & $221^{\mathrm{a}}(109)$ & $257^{\mathrm{a}}(141)$ & $198^{\mathrm{a}}(96)$ & $287^{\mathrm{a}}(105)$ & $240(117)$ \\
\hline
\end{tabular}

$\overline{a, b}$ Letras iguais na mesma linha, denotam ausência de diferença significante $(\mathrm{P}<0,05)$.

Quadro 2. Valores da média e do desvio padrão das concentrações sérica de uréia, creatinina, sódio e potássio de cada um dos grupos etários e geral, obtidos de fêmeas ovinas sadias, da raça Santa Inês, criadas no Estado de São Paulo

\begin{tabular}{lccccc}
\hline Variável & Grupo 1 & Grupo 2 & Grupo 3 & Grupo 4 & Geral \\
\cline { 2 - 6 } & \multicolumn{5}{c}{ Média (desvio padrão) } \\
\hline Uréia(mg/dL) & $14,86^{\mathrm{a}}(4,96)$ & $43,4^{\mathrm{b}}(17,82)$ & $38,53^{\mathrm{b}}(25,18)$ & $37,20^{\mathrm{b}}(12,02)$ & $32,33(19,81)$ \\
Creatinina(mg/dL) & $1,09^{\mathrm{a}}(0,12)$ & $1,34^{\mathrm{b}}(0,12)$ & $1,37^{\mathrm{b}}(0,24)$ & $1,14^{\mathrm{a}}(0,14)$ & $1,22(0,20)$ \\
Sódio(mmol/L) & $148,4^{\mathrm{a}}(5,0)$ & $146,5^{\mathrm{a}}(4,0)$ & $147,0^{\mathrm{a}}(6,1)$ & $140,1^{\mathrm{a}}(14,5)$ & $145,7(8,8)$ \\
Potássio(mmol/L) & $6,19^{\mathrm{a}}(0,90)$ & $4,82^{\mathrm{a}}(0,56)$ & $5,94^{\mathrm{a}}(2,00)$ & $4,91^{\mathrm{a}}(0,54)$ & $5,50(1,30)$ \\
\hline
\end{tabular}

$\overline{a, b}$ Letras iguais na mesma linha, denotam ausência de diferença significante $(\mathrm{P}<0,05)$.

Não foi encontrada diferença significativa entre os valores de sódio e potássio séricos entre os grupos, $(P=0,000)$ e $(P=0,000)$. A média observada para o sódio foi 145,70 , com desvio-padrão de 8,81. Para o potássio, a média observada foi 5,4942 com desvio-padrão de 1,3005.

\section{DISCUSSÃO}

São escassos os trabalhos que descrevem os valores de referência para as provas de avalição da função renal dos ovinos. Os valores encontrados neste estudo relativos a determinação da densidade urinária de ovinos saudáveis é semelhante com os estabelecidos por Carlson (1993) e Hendrix (2005) que variam de 1020 a 1050; o presente estudo possui resultados diferentes entretanto da afirmação de Carlson (1993) de que os animais mais jovens possuem valores mais baixos de densidade urinária podendo apresentar densidade menor que 1010.

Os valores médios encontrados para $\mathrm{pH}$ urinário neste trabalho encontram-se de acordo com os estabelecidos pela literatura que podem variar de 6 a 8,5 (Carlson 1993, Garcia-Navarro 1996, Hendrix 2005). Ferreira et al., 2014 encontrou valores menores de pH em relação a este trabalho.

Comparando os resultados de teores de ureia de animais adultos deste trabalho com os de Bickhardt et al. (1994) e Bickhardt et al. (1995) que estudaram os valores de referência da função renal em diferentes raças de corte e na raça Merino, este encontrou um valor médio de $4,14 \mathrm{mmol} / \mathrm{l}(24,93 \mathrm{mg} / \mathrm{dL})$ para a ureia sérica, concentração menor do que a encontrada nesta pesquisa. Notou-se que no presente estudo, ovinos da raça Santa Inês, o grupo 1 , animais de 0 a 6 meses, apresentou diferença em relação aos outros grupos, os valores encontrados foram menores quando comparado aos animais mais velhos. Sugere-se que embora estes animais sejam lactentes e tenham maior aporte de proteínas na dieta, o fato destes estarem em crescimento, envolva maior síntese proteica, maior consumo de proteínas biodisponíveis e maior assimilação de nitrogênio. Souza et al. (2014) estudando a dinâmica pré e pós-colostral de parâmetros bioquímicos em cordeiros também encontraram teores de uréia semelhantes encontrados nesta pesquisa em animais mais jovens. Madureira et al., 2013 encontraram valores superiores de uréia em estudo de ovinos da raça Dorper no estado da Bahia.

Soares (2011) notou valores superiores de ureia sérica aos que foram encontrados nesta pesquisa. Não foi encontrado descrito na literatura valores de ureia urinária em ovinos para que se pudesse comparar com os dados deste estudo. Em relação à concentração sérica de creatinina Coles (1986) e Brinkhof (2010) estudando as provas de avaliação da função renal encontraram que em diferentes raças de corte e na raça Merino valores médios semelhantes aos encontrados nesta pesquisa. Ao estudar os animais em diferentes fases da lactação e gestação encontraram influência destes estados fisiológicos, tendo sido observado aumento dos valores médios de creatinina em animais gestantes e lactantes. No presente trabalho, em animais jovens e impúberes, grupo 1 , os valores encontrados não foram diferentes aos encontrados em animais mais velhos e em reprodução, grupo 4, não sendo possível corroborar essa afirmação. Soares (2011) definiu como valores basais para animais adultos da raça Santa Inês um parâmetro superior ao encontrado nesta pesquisa; uma das razões pode estar relacionada ao fato de que em seu estudo só foram utilizados animais adultos, e no presente estudo a média foi calculada a partir do resultado obtido de animais de diferentes idades; e como a média dos animais lactentes apresentam um nível de creatinina menor do que o dos adultos, a média total estabelecida foi menor. 
Os valores médios encontrados para as concentrações sérica de potássio e sódio neste trabalho estão de acordo com os valores estabelecidos por Kaneko (2008), Fartashvand et al. 2012 e Ferreira et al., 2014.

0 estabelecimento de valores de referência para as provas de avalição da função renal dos ovinos é de grande importância para o clínico veterinário no auxílio da construção do diagnóstico das enfermidades que envolvam o sistema urinário desta espécie pois as enfermidades do sistema urinário possuem alta incidência como cistites, urolitíases e intoxicações por Cu (Riet-Correa et al. 2008, Ortolani et al. 2011, Antonelli et al. 2012, Ferreira et al., 2014). A escassez de trabalhos recentes neste tema ressalta a importância de que mais estudos sejam realizados.

\section{REFERÊNCIAS}

Antonelli A.C., Barreto Jr R.A., Mori C.S., Sucupira M.C.A., Marcello A.C.S. \& Ortolani E.L. 2012. Efeito de diferentes fontes energéticas na predisposição para urolitíase em cabritos. Ciênc. Anim. Bras. 13:487-493.

Araújo P.B., Pereira D.D., Teixeira M.N., Coelho M.C.O.C. \& Alencar S.P. 2009. Urinálise como instrumento auxiliar no diagnóstico de enfermidades em pequenos ruminantes. Med. Vet. 3(2):30-38.

Bickhardt K., Ganter M. \& Steinmann C.C. 1994. Klinische Nierenfunktionsuntersuchungen bei Schafen. III. Pathologische Funktiosänderungen bei Nephropathien der Schafe sowie bei der Urolithiasis der Schaf- und Ziegenböcke. Tierärztl. Wochenschr. 102:59-64.

Bickhardt K., Ganter M. \& Steinmann C. 1995. Clinical examination of renal function in sheep. III. Pathological changes of function in nephropathies of sheep and in the urolithiasis of rams and billy goats. Dtsch. Tierärztl. Wochenschr. 102(1):59-64.

Brenner B.M. \& Rector F.C. 1991. The Kidney. W.B. Saunders, Philadelphia. 2653p.

Brinkhof J.M.A., Houwers D.J., Moll L., Dercksen D. \& Van Maanen C. 2010. Diagnostic performance of ELISA and PCR in identifying SRLV-infected sheep and goats using serum, plasma and milk samples and in early detection of infection in dairy flocks through bulk milk testing. Vet. Microbiol. 142(3/4):193-198.

Carlson G.P. 1993. Testes Bioquímicos, p.295-423. In: Smith B.P. (Ed.), Tratado de Medicina Interna de Grandes Animais. Manole, São Paulo.

Coelho B.M.P., Ikesaki J.Y.H., Simões D.M.N., Kanayama L.M., Guerra J.L. \& Kogica M.M. 2001. Insuficiência renal crônica em cães jovens: estudo clínico de 25 casos. Revta Clín. Vet. 33:52-56.

Coles E.H. 1986. Veterinary Clinical Pathology. 4th ed. W.B. Saunders, Philadelphia. 486p.

Diéz J. \& Biollaz J. 1979. Renal function tests in experimental toxicity studies. Pharmacol. Ther. 5:135-145.

Duncan J.R. \& Prasse K.W. 1977. Veterinary Laboratory Medicine. Press ISU, Ames. 392p.

Fartashvand M., Mousavi G., Assadnassab G. \& Hajisadeghi Y. 2012. Surgical induction of experimental chronic renal failure in the sheep. Annals Biol. Res. 3(11):5013-5018.

Ferreira D.O.L., Santarosa B.P., Sacco S.R., Dias A., Amorim R.M. , Chiacchio S.B., Lisbôa J.A.N. \& Gonçalves R.C. 2014. Efeito da suplementação de cloreto de amônio sobre os equilíbrios eletrolítico e ácido-básico e o pH urinário de ovinos. Pesq. Vet. Bras. 34(8):797-804.

Garcia-Navarro C.E.K. 1996. Manual de Urinálise Veterinária. Varela, São Paulo. 96p.

Garry F., Chew D.J. \& Hoffsis G.F. 1990a. Urinary indices of renal function in sheep with induced aminoglycoside nephrotoxicosis. Am. J. Vet. Res. 51:420-427.
Garry F., Chew D.J. \& Hoffsis G.F. 1990b. Enzymuria as an index of renal damage in sheep with induced aminoglycoside nephrotoxicosis. Am. J. Vet. Res. 51:420-427

Greco D.S., Turnwald G.H., Adams R., Gosset K.A., Kearney M. \& Casey H. 1985. Urinary gamma-glutamyl transpeptidase activity in dogs with gentamicin-induced nephrotoxicity. Am. J. Vet. Res. 46:2334-2335.

Hagiwara M.K. \& Mamizuka E. 1998. Estudo clínico da doença do trato urinário inferior em gatos doméstico de São Paulo. Braz. J. Vet. Res. Anim. Sci. 35(2):69-74.

Hendrix C.M. 2005. Procedimentos Laboratoriais para Tecnicos Veterinários. 4th ed. Rocca, São Paulo. 568p.

John E. 2003. Sample Size Estimation: how many individuals should be studied? Res. Stat. Anal. 227:309-313.

Kaneko J.J. 2008. Clinical Biochemistry of Domestic Animal. 6th ed. Academic Press, San Diego. 928p.

Korzun W.J. \& Miller W.G. 1987. Sodium and potassium, p.86-91. In: Pesce A.J. \& Kaplan L.A. (Eds), Methods in Clinical Chemistry. Mosby, Missouri.

Lustgarten J.A. \& Wenk R.E. 1972. Simple, rapid, kinetic method for serum creatinine measurement. Clin. Chem. 18:1419-1422.

Madureira K.M., Gomes V., Brenda Barcelos B., Breno Zani B.H., De Lara Shecaira C., Baccili C.C. \& Benesi F.J. 2013. Parâmetros hematológicos e bioquímicos de ovinos da raça Dorper Hematological and biochemical parameters of Dorper ewes. Semina: Ciênc. Agrárias 34(2):811-816.

Meira Jr E.B.S., Rizzo H., Benesi F.J. \& Gregory L. 2009. Influência dos fatores sexuais e etários sobre a proteína total, fração albumina e atividade sérica de aspartato-aminotransferase e gama-glutamiltransferase de ovinos da raça Santa Inês. Bras. J. Vet. Res. Anim. Sci. 46(6):448-54.

Ortolani E.L, Machado C.H., Minervino A.H.H., Barreto-Júnior R.A. \& Headley S.A. 2011. Clinical observations and acid-base imbalances in sheep during chronic copper poisoning. Semina, Ciênc. Agrárias 32:11231132.

Osborne C.A. \& Lees G.E. 1995. Bacterial infections of the canine and feline urinary tract, p.757-97. In: Osborne C. \& Finco D.R. (Eds), Canine and Feline Nephrology and Urology. Elsevier Saunders, St Louis, Missouri.

Pinheiro R.R., Hagiwara M.K., Kogika M.M. \& Benesi F.J. 1990. Alterações renais funcionais em caprinos submetidos à infusão intravenosa de hemolisado. Braz. J. Vet. Res. Anim. Sci. 27:57-64.

Polzin D.J., Osborne C.A., Jacob F. \& Ross S. 2001. Chronic renal failure, p.1634-1662. In: Ettinger S.J. \& Feldman E.C. (Eds), Textbook of Veterinary Internal Medicine. 4th ed. W.B. Saunders, Philadelphia.

Reichmann C.E. 1972. Contribuição ao estudo do quadro leucocitário sanguíneo de ovinos (Ovis aries) normais, criados no estado de São Paulo: influências de fatores raciais e etários. Dissertação de Mestrado, Universidade de São Paulo, SãoPaulo, SP. 115p.

Riet-Correa F., Simões S.D.V. \& Vasconcelos J.S. 2008. Urolitíase em caprinos e ovinos. Pesq. Vet. Bras. 28(6):319-322.

Rosenberger G. 1993. Exame Clínico dos Bovinos. 3aㅡ ed. Guanabara Koogan, Rio de Janeiro. 420p.

Schrier R.W., Wang W., Poole B. \& Mitra A. 2004. Acute renal failure: definitions, diagnosis, pathogenesis, and therapy. J. Clin. Invest. 114:5-14.

Soares P.C. 2011. Efeitos da intoxicação cúprica e do tratamento com tetratiomolibdato sobre a função renal e o metabolismo oxidativo de ovinos. Tese de Doutorado em Medicina Veterinária, Faculdade de Medicina Veterinária e Zootecnia, Universidade de São Paulo, São Paulo, SP. 117p.

Souza D.F. de., Monteiro A.L.G., Dittrich R.L., Schmidt E.M. dos. S., Fernandes S.R. \& Beltrame O.C. 2014. Dinâmica pré e pós-colostral de parâmetros bioquímicos em cordeiros. Cienc. anim. bras., Goiânia, 15(3):313-321.

Talke H. \& Schubert G.E. 1965. Enzymatische Harnstoffbestimmung in Blut und Serum in optishem Test nach Warburb. Klin. Wochenschr. 43(174):174-175. 